

\title{
EQUITY, DIVERSITY, AND INCLUSION IN NATIONAL SECURITY INTELLIGENCE
}

Date: November 23, 2021

Disclaimer: This briefing note contains the encapsulation of views presented by the speaker and does not exclusively represent the views of the Canadian Association for Security and Intelligence Studies.

\section{KEY EVENTS}

On November 23, 2021, Mr. Artur Wilczynski, Associate Deputy Chief at Communications Security Establishment (CSE), presented on Equity, Diversity, and Inclusion in National Security Intelligence at the 2021 CASIS Vancouver West Coast Security Conference. This presentation was followed by a question and answer period and a breakout room session with questions from the audience and CASIS Vancouver executives. The key points discussed included how a lack of diversity in intelligence can negatively contribute to Canada's national security, how diversity broadens the effectiveness of organizations, and how Canadian national security institutions must be in service to all Canadians.

\section{NATURE OF DISCUSSION}

\section{Presentation}

Mr. Wilczynski focused on how a lack of diversity in the workforce negatively affects Canadian intelligence organizations and how diversity can broaden organizational efficiency and fulfil their core mandates. Mr. Wilczynski also touched upon the damage done by the LGBT Purge.

\section{Question Period/Breakout Room Discussion}

Mr. Wilczynski discussed the importance of representation in the intelligence community and some of the skills that he considered essential for analysts. The importance of recognizing past wrongdoings by the intelligence and national security community was also discussed. 


\section{BACKGROUND}

\section{Presentation}

Mr. Wilczynski began his presentation by stating that a lack of diversity in the study and practice of intelligence is a critical aspect that impedes an organization from effectively managing risk and impacts every step of the intelligence process. This lack of diversity, therefore, negatively contributes to Canada's national security.

Mr. Wilczynski examined the history of Canadian intelligence, including CSE and its role since the Second World War. Prior to the conception of CSE, the Communications Branch of the National Research Council (CBNRC) was its predecessor. Since the Second World War, CSE has provided signals intelligence (SIGINT) in Canada, which surprised the world through its efficacy. CSE was placed under the Department of National Defence, where they provided information advantages to Canadian policy and decision makers. Today, CSE is involved with the cyber world, effectively using it as a wheelhouse.

CSE works most effectively and efficiently when there is diversity in its teams. Broader or more diverse ranges of people allows different perspectives and backgrounds to be brought to the table for solutions. A diverse workforce also reflects the society it serves, allowing the organization to fulfil its core mandates in the eyes of the public. An organization cannot fulfil its core mandates if it is out of touch, racist, or sexist.

CSE wants to implement changes to address the legacy of exclusion and reflect the country it is designed to serve. As a result, the CSE is developing a new framework for equity, diversity, and inclusion to ensure barriers are eliminated. Gender-based Analysis Plus, which is a formal governmental process that reviews policies and practices to ensure they remove barriers and promote equity, is a crucial part in addressing exclusion.

Mr. Wilczynski further reflected on how he, as a LGBT person, was excluded from national security and intelligence by the LGBT Purge when he first joined the public service. In addition, he was an immigrant from Poland and the idea of being a part of the national security community was unrealistic. Unfortunately, this kind of thinking is still present in young people from marginalized communities, but it needs to change. They need to know that their background will not be an impediment to their success within national security. The 
intelligence community must be more diverse and inclusive, as it would benefit by absorbing different perspectives and experiences.

Mr. Wilcyznski commented on how presentations by Black Canadians in the aftermath of the George Floyd, listening to Holocaust survivors share their experiences, and working with First Nations on the importance of reconciliation are important conversations to understand the reality and the challenges faced by people who are often underrepresented in public service.

Mr. Wilczynski concluded his presentation by highlighting that these conversations are worthwhile and make the CSE a better institution to serve the needs of the Canadian public, help build an inclusive community, and foster respect and inclusion. Most importantly, this work can help Canadians know that their national security institutions are a reflection of them and that their services and efforts are in service to all Canadians.

\section{Question Period}

During the question and answer period, Mr. Wilczynski noted that intelligence agencies need to go to where the talent is and make themselves known to the broad range of Canadians who are interested in the study and practice of intelligence. Diversity in perspectives is needed to critically approach the practice of intelligence. However, hiring is not enough; they need to know that they will be heard and that their voices matter, which can often be a challenge.

In regard to the essential skills an analyst must possess to deal with asymmetric challenges and new security problems, Mr. Wilczynski stated that the sense of curiosity is what he would look for first but knowing and understanding how to be brief is also very important when working among the intelligence community.

\section{Breakout Room Discussion}

During the breakout room discussion, Mr. Wilczynski talked about how the lack of acknowledgement of the negative history of the national security community's engagement with various communities such as Indigenous, radicalized, and LGBT, can be an obstacle in having a diverse workforce. When the experience of those communities has been negative and the intelligence organizations are not deliberate in addressing those experiences, it is difficult to retain and recruit from those communities. 
Mr. Wilczynski also noted that reaching out to historically marginalized communities is not always easy and will take some time. The national security and intelligence community needs to be determined and deliberate to reach out and convince those who have been wronged in the past- such as victims of the LGBT Purge - that the community has changed.

Mr. Wilczynski further expanded on the effectiveness of intelligence and argued that increased transparency can help Canadian national interests. One method is to listen, support, and carve a pathway to gain insight from employees' experiences to help guide them. Having public conversations to promote transparency helps to tackle issues and expands on the value of having frank and open dialogue of intelligence and security intentions and missions. Understanding what is expected from government agencies and individuals will help address the gap between a disaggregated response and identify a possible course of action for reconciliation. A simple survey cannot accomplish this as the range of responses is disaggregated based on their backgrounds, sexual orientation, and racial community.

\section{KEY POINTS OF DISCUSSION}

\section{Presentation}

- A lack of diversity negatively contributes to Canadian national security.

- CSE provides information advantages to Canadian policy and decision makers.

- Diversity in the workforce enables broader or more diverse ranges of people to allow for different perspectives and backgrounds to contribute to problem solving.

- CSE is developing a new framework for equity, diversity, and inclusion to ensure barriers are eliminated.

- National security institutions must be a reflection of and in service to all Canadians.

\section{Question Period}

- Intelligence agencies need to expand their search for talent by reaching out to the broad range of Canadians that have an interest and knack for the practice of intelligence.

- Diversity in perspectives is needed to critically approach the practice of intelligence. 
- Two important skills necessary for addressing security problems in the intelligence field are a sense of curiosity, as well as understanding how to be concise.

\section{Breakout Room Discussion}

- Lack of acknowledgement of the negative history of the national security community's engagement with various communities can be an obstacle in having a diverse workforce.

- The national security and intelligence community needs to be determined and deliberate to reach out and convince those who have been wronged in the past that the community has changed.

- Understanding expectations from government and individuals will help address the gap between a disaggregated response and identify a possible course of action for reconciliation.

(c) (†) $\ominus$

EY NC ND This work is licensed under a Creative Commons Attribution-NonCommercial-NoDerivatives 4.0 International License.

(C) (ARTUR WILCZYNSKI, 2022)

Published by the Journal of Intelligence, Conflict, and Warfare and Simon Fraser University

Available from: https://jicw.org/ 